\title{
Experimental Research on Biorobotic Autonomous Undersea Vehicle
}

\author{
Jianhong Liang, Hongxing Wei, Tianmiao Wang, Li Wen, \\ Song Wang and Miao Liu \\ BEIHANG University \\ China
}

\section{Introduction}

On August 2004, the SPC-II robofish, developed by the Robotics Institute in Beijing University of Aeronautics and Astronautics, was used for aiding underwater archaeology in an experiment at the shipwreck site of Donggu gulf in Dongshan Island, Fujian Province. This experiment is not only the combination achievement of many subjects such as bionics, robotics, archaeology, oceanology, and so on, but also the first attempt to apply bionic propulsive mechanism to the real problem.

Fernandez. Benoit, the pioneer of underwater archaeology in France, had said that "the biggest museum in the world is the sea-bottom" [1]. China is an ancient civilization country with a history of more than 5000 years. The voyage technique was used to be vigorous and business on the sea was very frequent, so we can imagine that there are abundant of cultural relic imbedded in the 3,000,000 sq. km sea area. In 1987, the laboratory of underwater archaeology was founded by the historical museum of China and then the first team of underwater archaeology was founded in China in 1990[1].

Now the underwater archaeology procedure can be divided into three phases. The first is large-scope searching. Usually the equipments such as sonar are carried by archaeological ship to find the doubtful site. Sometimes this work can be replaced by the information offered by fisherman. The second is the site validation. The equipments such as lighting and vidicon were carried to the sea-bottom to do close observation, and the pictures or sample objects are sent back to do more analyses. The third is salvage and excavation. It need long time to do underwater work such as divide region, clear bed load, recover site, salvage cultural relic and so on.

In the above three phases, the last two are more pivotal and need to be performed on the sea-bottom. Normally they are completed by the archaeological team members. It can be seen that underwater work plays an important role in the task of underwater archaeology. Because of the restriction of human body physiology (narcosis of nitrogen), generally people can only dive to $60 \mathrm{~m}$ to $70 \mathrm{~m}$ in depth. And meanwhile people are weightless in the water, movement inconvenience, overdraft of physical strength, short duration, and needing long time to be decompressed, all make the work inefficient[2]. The early underwater archaeology was difficult, and the deepwater archaeology was almost impossible in a manner. 
The development of underwater robotic technology brought new chance to underwater archaeology. In 1989, Doctor Robert Ballard in U.S. used a ROV named 'Jason' to investigate an old shipwreck site in Med and 'Jason' successfully screened the shipwrecks photograph from the sea-bottom 800 meters under water. With the help of underwater robot, archaeological team can explore anywhere without the danger of life. In recent twenty years, China has also paid more attention to the development of underwater robotic technology. With the development of underwater archaeology and the high need of equipments, underwater robots are gradually applying to underwater archaeology. In 2001, in the archaeological research of underwater old buildings in Fuxian lake of Yunnan province, ShenYang Institute of Automation used ROV named 'goldfish No.1' and AUV named 'CR$02^{\prime}$ for assistant diving to about 70 meters under water, to send real-time images of lakebottom back to archaeologist for analysis. Although the underwater robot (used for observation) can do the second phase work of archaeological team, it is still difficult to replace people to work in the third phase, which is an important research topic of underwater robot in the future (used for busywork).

SPC-II is an underwater robot using bionic propulsive mechanism. Compared with thruster of traditional screw propeller, it has some traits such as high efficiency, good maneuverability, low noise, manipulation's facility, small dimension and weight, etc. Concern to the trait of SPC-II, this paper discussed the feasibility of underwater work, and a scheme that SPC-II can help to complete the second phase work of underwater archaeology was proposed, which was validated by experiment. In the end the improvement method was summarized.

\subsection{Requirement of underwater archaeology to UUV}

Because of the particularity of the environment and objects of underwater archaeology, there are some special demands for the robot and the equipment, which are described as follows:

The disturbance and destruction to the environment should be as little as possible. It is hard to avoid shuttling in the site back and forth when the underwater robot is working and the result would be serious if the cultural relic was shattered. The silt aroused by disturbance can also affect the collecting of image information. The robofish, adopted the bionic propulsion, has its own advantages compared to the traditional screw propeller. In addition, the electric cable of ROV is a potential trouble, and the crawling robot and daggling robot do not adapt to the archaeology.

Convenient equipments should be prepared for the task. The exploration apparatus and other equipments must be equipped for the underwater robot for archaeology, and they must not do harm to the cultural relic. Generally the underwater TV and sonars are used. But the working depth of underwater TV is limited, and it must work with headlamp when the depth is more than 15 meters. Sonar is the dominant equipment for underwater exploration[3]. Figure1 (a) and (b) are the images returned from underwater TV and sidescan sonar, both of which have their advantages and disadvantages respectively. The sight depth of the underwater TV is short and the eyeshot is small but the image is legible; and the image of the side-scan sonar is blurry but the sight depth is long and the eyeshot is wide. If the underwater robot was applied to the third phase of underwater archaeology, the equipments, such as machinery arm, manipulator and special tools must be equipped with it. 


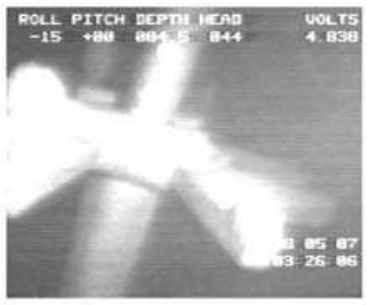

( a )

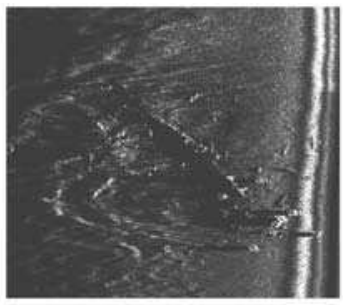

(b)

Fig. 1. Images from underwater archaeology

The Dynamic Positioning should be accurate. How to guide the underwater robot to the known target (accuracy) and how to hang around the target by propeller control in order to perform further step task after finding out target (repeatability), all of which need the support of underwater acoustical position system with high accuracy.

High maneuverability. It contains the maneuverability in horizontal (turning radius and turning rate) and vertical (rising and submergence). Usually the shipwreck site is rough and complex, so the robot maneuverability can guarantee the success of the archaeology task.

The robot should have local intelligence. It could track the sea-bottom landform and avoid obstacles (independently) autonomously. Generally, the stable depth of the underwater robot is relative to the sea level. But the archaeology exploration task needs to follow the contour line relative to the sea-bottom, which involves tracking of sea-bottom landform. In addition, for the sake of safety, the robot ought to have the capability to avoid obstacles independently.

The robot should have small size, light weight and low cost, which are considered from application and popularization. Robot with large size and heavy weight could bring trouble when putting and retrieving. In order to enhance the maneuverability, the underwater robot with traditional screw propeller usually need more than one thruster to produce the propulsion of vector, which makes not only the large size structure, complex control system, but also the high cost. Nevertheless the robofish has certain advantage because it produces the propulsion of vector directly by tail fin and is easier to integrate into a small size.

The control should be convenient and flexible. Generally, the operators do not know about the situation of sea-bottom when the underwater robot is carrying out the archaeology task, which are navigated by the images and information returned from underwater robot. As a result it needs the underwater robots have good maneuverability, which is also for security. Moreover, there are many common problems such as the real-time exchanging of information between the mother ship and underwater robot (underwater communication), the dynamic hermeticzation with high compression resistance, the ability of resisting ocean current and so on.

\subsection{Feasibility of SPC-II to perform underwater task}

1) Introduction of robofish SPC-II

The bionic propulsive underwater vehicle was researched in the Robotic Institute from 1999. "S.P.C.", which was brought forward on the basis of our many years' research and experience, is a design principle of the robot, which means that stability is superior. The series of SPC-Irobofishes, designed in "S.P.C." mode have attained good effect. SPC-II is the revised version of SPC-I, which was developed for some engineering application, but still in the phase of theory demonstrating and validating. 


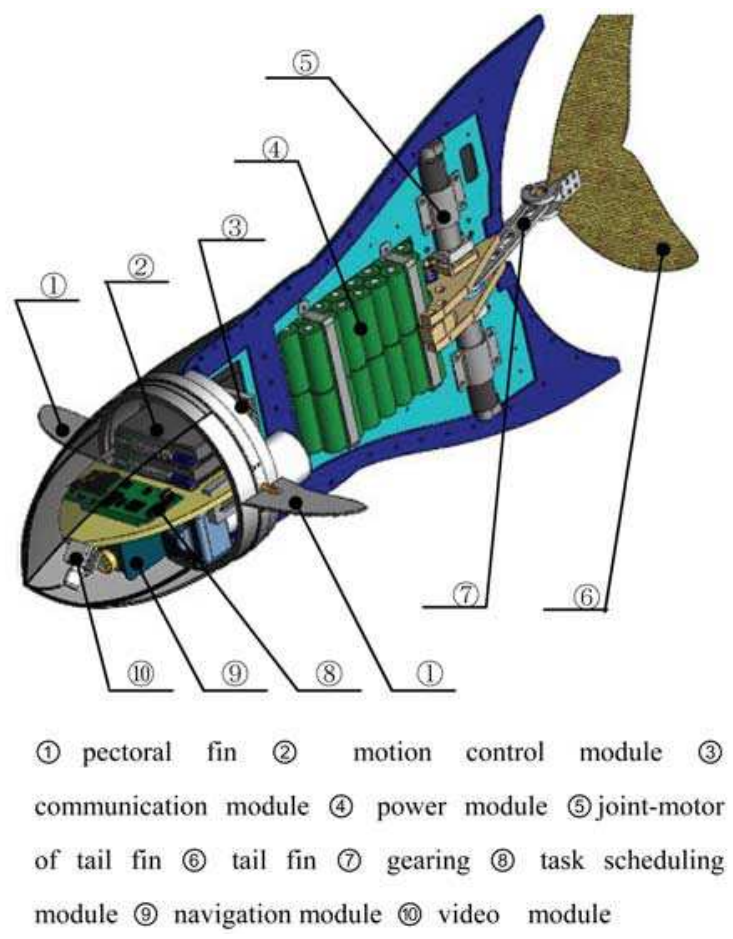

Fig. 2. General layout of SPC-II

SPC-II adopts streamline shape and FRP (Fiberglass-Reinforced Plastics) material. It is mainly consist of eight parts: console, communication module, mechanical reality, power module, task scheduling module, motion control module, navigation module and video module. The robofish can perform five basic actions of going ahead, turning left, turning right, rising and submergence, and it can achieve the function of course keeping, submergence maneuverability, swimming in certain depth, GPS navigation, video capture. Figure 2 is the general layout of SPC-II.

Figure 3 shows the system framework and data flowing.

In order to communicate with SPC-II conveniently, we develop the console software based on PC. The main functions are as follows:

System Monitoring. It can check the work state, water leak state and system communication state periodically, and raise the alarm when there is abnormity.

Setting Parameters. Regulating the swimming parameters of robofish, and setting sea route and constituting the task.

Dynamic Manipulation. Real-time Controlling heading, velocity, ascending or submergence of the robofish, and showing the information returned from sensor in graphics mode synchronously.

Data recording. Record the information of swimming track, image, system state and so on. Figure 4 is the main interface of the console software, which can be divided into several areas according to function. The main manipulation is related with function keys of the keyboard and the operation is simple, speedy and agile. 


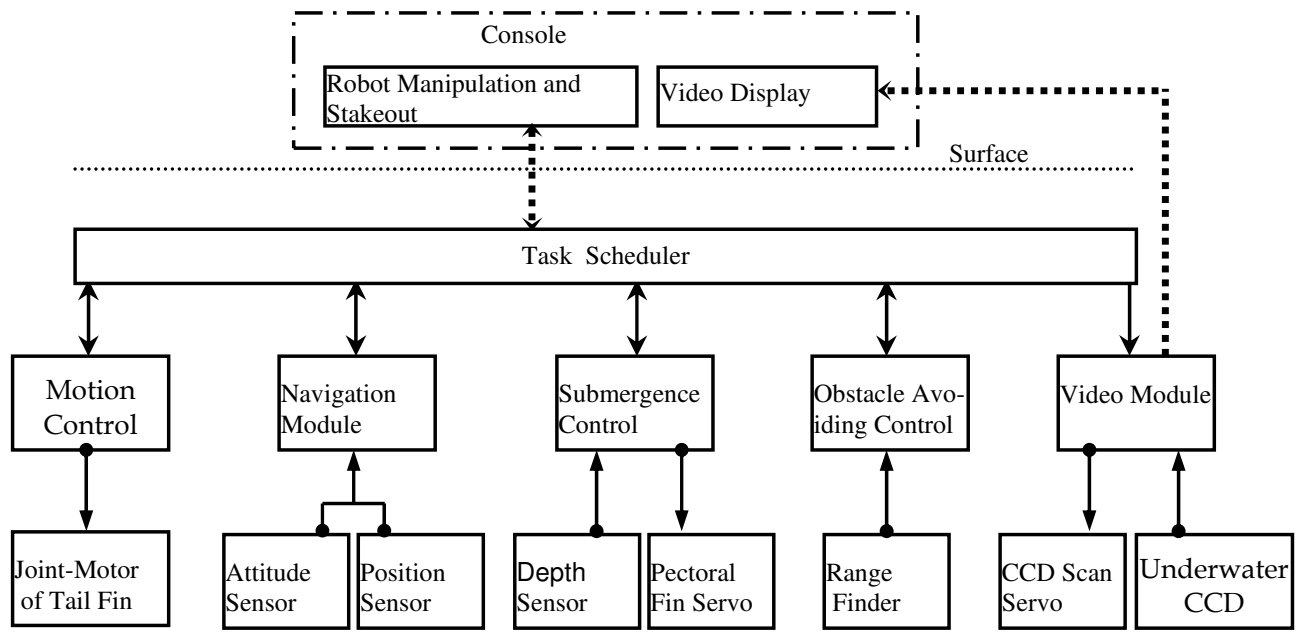

Fig. 3. System framework

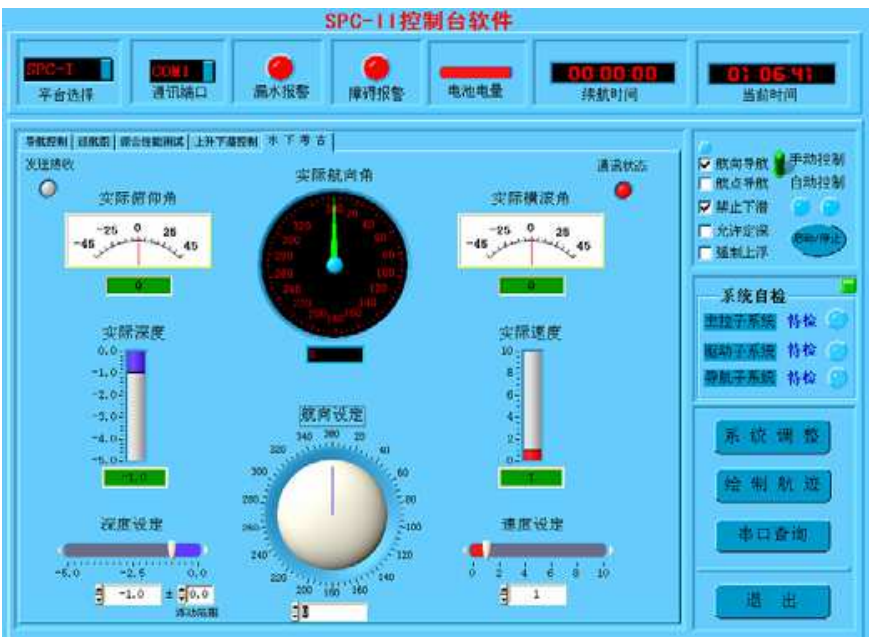

Fig. 4. Main interface of console software

2) feasibility of executing underwater task

The robofish SPC-II adopt two servo-joints that are controlled separately. It is benefited to regulate the tail locomotion parameters accurately and obtain better flicking waveform. SPC-II reaches a steady speed of $1.4 \mathrm{~m} / \mathrm{s}$ at frequency of $2.5 \mathrm{~Hz}$ and its proportion of velocity to body length is more than $1 \mathrm{~L} / \mathrm{s}$.

Flexible multi-joint fish robot has been proved to have perfect maneuvering performance. For example, 4-joint VCUUV turns at $75 \%$ s with one body length in comparison with 7 
body lengths of a conventional UUV [4]. SPC-II with rigid body is reduced to only 2 joints, but it still can easily turns with 1 body length turning radius. Usually the small turning radius can obviously improve the efficiency of UUV's employment. Moreover, SPC-IIuses 2 elevators fixed to the part of pectoral fin to dive.

SPC-II carries power battery itself and can communicate with console through cable or wireless style, which makes the transformation between ROV(Remotely Operated Vehicle) and AUV(Autonomous Underwater Vehicle) very simple. Compared with the conventional ROV, SPC-II has the character of higher sailing speed; and compared with the conventional AUV it also has the merit of small size, good maneuverability, and flexible manipulation. At present SPC-II was equipped with a kind of nickel-hydrogen pile $(48 \mathrm{~V}, 500 \mathrm{wh})$, with which SPC-II could cruise about 3.5 hours ( at $2 \mathrm{kts}$.). If the lithium pile with the same volume $(48 \mathrm{~V}, 1000 \mathrm{wh})$ is used instead, the cruising time could reach 7 hours.

The comparison between SPC-IIand some other UUVs is described as Table1. Besides, SPCII still reserves a loading room of $9 \mathrm{~kg}$ for some special task, which means it still can be added relevant equipment according to real requirement. At a word, SPC-II can perform simple underwater task after proper refitting and has its own advantages and specialties in efficiency and quality.

\begin{tabular}{cccc}
\hline \hline $\begin{array}{c}\text { Name/ } \\
\text { Manufacturer }\end{array}$ & $\begin{array}{c}\text { CR-01(AUV) } \\
\text { / ShenYang Institute } \\
\text { of Automation }\end{array}$ & $\begin{array}{c}\text { VCUUV/ } \\
\text { Lab of C.S.Draper }\end{array}$ & $\begin{array}{c}\text { SPC- II } \\
\text { /Robot Research } \\
\text { institute of BUAA }\end{array}$ \\
\hline $\begin{array}{c}\text { Length/ } \\
\text { Displacement }\end{array}$ & $4.374 \mathrm{~m} / 1305 \mathrm{~kg}$ & $2.4 \mathrm{~m}$ & $1.21 \mathrm{~m}$ \\
Battery & $10 \mathrm{~h}$ & $/ 136 \mathrm{~kg}$ & $/ 40 \mathrm{~kg}$ \\
Duration & $6000 \mathrm{~m}$ & $3 \mathrm{~h}$ & $3.5 \mathrm{~h}$ \\
Dive Depth & $2 \mathrm{kts}$ & $10 \mathrm{~m}$ & $5 \mathrm{~m}$ \\
Maximum & - & $2.4 \mathrm{kts}$ & $2.8 \mathrm{kts}$ \\
Velocity & - & $75^{\circ} / \mathrm{s}$ & $70^{\circ} / \mathrm{s}$ \\
Turning Rate & - & $/ 1 \mathrm{~L}$ & $/ 1 \mathrm{~L}$ \\
/ Radius & $-32 \%$ & $10 \%$ \\
Propeller/ & & & \\
Displacement & & & \\
\hline \hline
\end{tabular}

Table 1. Comparison between some UUVs

\subsection{Underwater archaeology experiment}

At present, SPC-II can elementarily fulfill the need of underwater archaeology and it also has some advantages in environment disturbance and horizontal maneuverability. But the ascending and submergence of SPC-II are implemented by changing the pectoral fin's incidence angle, so it can dive only in the process of swimming (submergence velocity is the minimum straightforward velocity of submergence). In addition, it can not swim back off and hasn't the underwater position system. All of which bring more difficulty to underwater pointing task. Moreover, SPC-II is only a robot prototype with simple equipments; it can only help the archaeological team to complete the second phase task.

Donggu gulf site of shipwrecks in Dongshan city, Fujian Province is in a gulf, and the offing is much calm, but the water quality is much turbid (especially when is ebbing). The position of site has been known that is in less than 5 meters. The benthal hypsography likes gently 
brae, and the diffused china, iron weapon and ships were enchased or buried in silt. The purpose of our attempt is to let the robotfish dive to the site and capture and feedback the valuable underwater image information by the vidicon. The implementing methods are described in detail as follows.

1) Experiment scheme of robotfish aided underwater archaeology

The communication chain between the SPC-II and the console was properly modulated. As a result, the communication with cable and the wireless communication are both adopted (buoy and radio-communication as shows in figure. 5). This method not only saves the expensive underwater communication sonar, but also avoids the encumbrance result of too long cable.

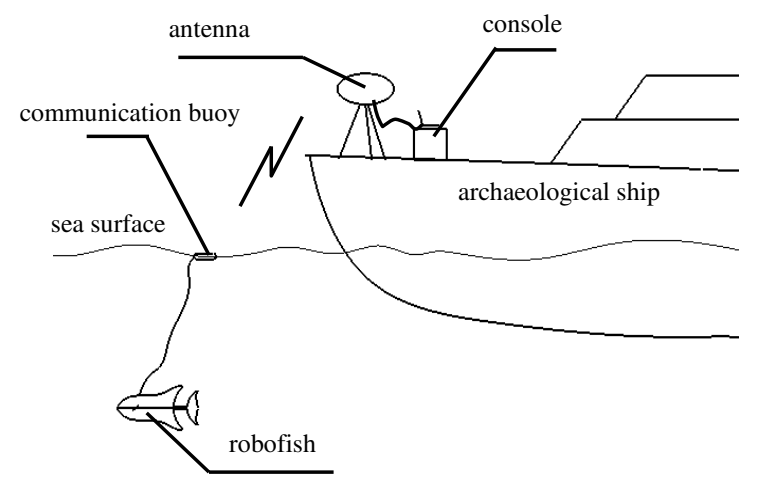

Fig. 5. Sketch map of system communications

The method of hover submergence to explore the object was developed, which would resolve the problem that SPC-II could not hang when swimming and could not ascend and dive vertically. Because the turning radius of robotfish is small and the spiral velocity is slow, and the robotfish can keep swimming in stable depth, it can screen the object distinctly from any directions. The process can be divided into two steps: 1) arriving aim area; 2) scanning and searching unidentified objects. It can be decomposed into several sequences of robot actions or control operations. First the robotfish swam on the sea level at high speed to reach the above of the aim area with GPS navigation; then it spirally dived to appointed depth in short turning radius (Figure 6 (a)). And now the robot had reached the aim area. Two measures were implemented for scanning and searching unidentified objects. The first is that the robotfish hovered in stable depth at diving velocity and gradually augmented the hover radius along the involutes (Figure 6 (b)). Moreover the second is that it swam out and home in stable depth at diving velocity and gradually made lateral move (Figure 6 (c)).

The robofish started the video module to capture and the console started to monitor synchronously and recorded the video information during the process mentioned above. Once discovering the questionable objects, the robot hovered at the place and modulated the submergence depth in order to receive more clearly and abundant image information. But in practice, the sea-bottom gradient is changing and SPC-II does not have the ability of landform tracking, so the searching effect in stable depth (3 meters) was not perfect, and it usually appeared the phenomenon that the level of sea-bottom had overstepped the 
camera's eyeshot. Consequently, the method, that SPC-II swam in the ordered height little higher than sea bottom and explored the sea-bottom all the time, was proposed. It had been proved to be much fit for the even landform.

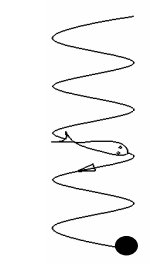

(a)hovering

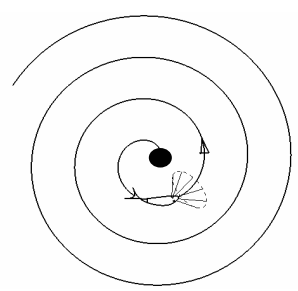

(b) hovering scan

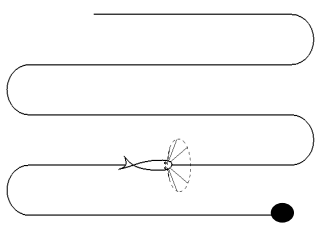

(c) traversing scan

Fig. 6. Methods of robofish aided archaeology

2) Experimental result

The practice has proved that the strategy mentioned above is feasible. The robofish can dive to target area to search and can cover it on the whole, at the same time, the images of target are returned. But the efficiency is low and the eyeshot of single image is too narrow, which could not form the panorama vision yet. Comparison of the two measures for searching questionable objects has shown that the efficiency of the first is higher than the second in theory, but its control is complex, and the robofish is hard to swim according to the scheduled track, which could result in omitting repeating scanning. But the operating of the second is easier compared to the first. Table 2 gives the result of several methods of searching for an square area of about 200 square meters.

\begin{tabular}{|c|c|c|c|}
\hline \multicolumn{2}{|c|}{ Search Method } & $\begin{array}{c}\text { Time } \\
\text { Consumed }\end{array}$ & $\begin{array}{l}\text { Number of } \\
\text { dubious site }\end{array}$ \\
\hline \multirow{6}{*}{$\begin{array}{l}\text { Hovering } \\
\text { Scan }\end{array}$} & Keeping & & \\
\hline & Settled & $773 \mathrm{~s}$ & 6 \\
\hline & Depth & & \\
\hline & Keeping & & \\
\hline & Close to & $955 \mathrm{~s}$ & 10 \\
\hline & Sea-bottom & & \\
\hline \multirow{6}{*}{$\begin{array}{l}\text { Traversing } \\
\text { Scan }\end{array}$} & Keeping & & \\
\hline & Settled & $843 \mathrm{~s}$ & 7 \\
\hline & Depth & & \\
\hline & Keeping & & \\
\hline & Close to & $1102 s$ & 15 \\
\hline & Sea-bottom & & \\
\hline
\end{tabular}

Table 2. Comparison between the results of different methods

It is obvious that although the helical scan wasted less time than out and home scan, but the information of the image returned was little, which was the result of area omitting, and which was almost unavoidable in the condition of manual operating. Moreover, exploring the bottom could find more questionable objects than searching in certain depth, but the cost 
was that it raised the benthal deposit and influenced the quality of images. Once the robot was equipped with underwater positioning system and side sonar, it would achieve the autonomous swimming of the foregone trace and the tracking of benthal landform, which would improve the exploration efficiency and quality.

Figure 7 shows a questionable picture returned from SPC-II. Since the seawater is turbid and the target is too close to the lens, its field is very blurry.

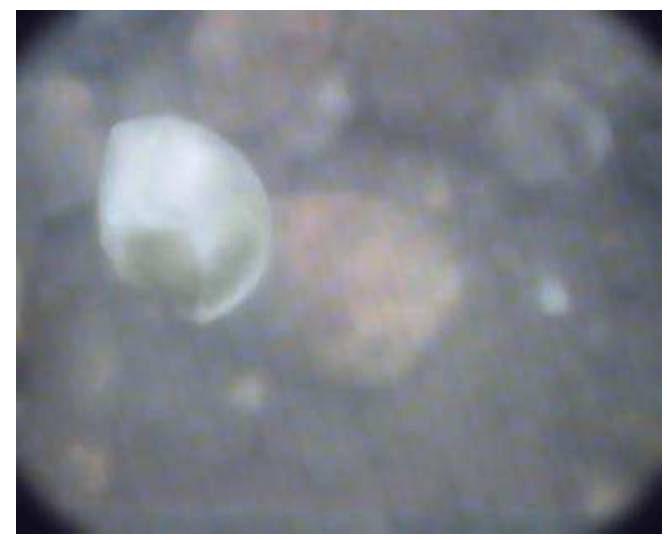

Fig. 7. One returned image from robofish

\subsection{Conclusion}

Underwater archaeology experiments have validated the performance of SPC-II. Meanwhile, some problems have been exposed, which referred to Dynamic Positioning, maneuverability (vertical), communication, configuration of functional devices and diving depth, etc. All these problems supply references to future researchers. To serve the underwater archaeology better, and build basis for the future complicated applications, the robofish SPC-II should be improved properly. The details are described as follows.

1. Add an underwater positioning system. Influenced by ocean current and stormy waves, the existing dead reckoning error is unacceptable. It makes the acoustic positioning system necessary. This system is also strongly required for dynamic positioning.

2. Improve the maneuverability of vertical plane. One of the diving methods is changing its own weight, but it is difficult to respond dynamically; and the other is changing the incidence angle of pectoral fins, but it requires a certain speed. In order to dive faster and vertically, it is considered to replace the pectoral fins with two vertical screw propellers.

3. Add high-performance functional devices such as high accuracy and wide-eyeshot CCD cameras, side-scan sonar, robot arms, manipulators, etc.

4. The diving depth. The target depth is set to 100 meters. Most of sites under water are within this range.

5. Optimize local intelligence. This needs to upgrade the corresponding sensors and improve algorithms. 


\section{Propulsive and maneuvering performance of two joints biorobotic autonomous undersea vehicle SPC-III}

\subsection{Introduction}

Intensive study has been carried out in respect of the outstanding swimming skill of some marine animals such as dolphin and tuna in the recent 20 years. Focusing on their prime propulsion device, i.e. their caudal fin, the researchers has preliminarily found out the locomotion of body-caudal fin and hydrodynamic principle [5] [6]. Parameter range has even been worked out to achieve optimum kinematics of caudal fin flipping by conducting modeling, simulation calculation and model experiment in the pool [7][8][9][10]. The results of these researches have facilitated the birth of the Prototype of mission-scale biorobotics autonomous undersea vehicle. Low speed maneuverability, lower noise and high efficiency have become hot issues [11]. Anderson et al. developed the Vorticity Control Unmanned Undersea Vehicle. The 2.4m -long VCUUV follows the morphology and kinematics of a yellow fin tuna and adopt hydraulic-power 4 joints tail drive structure. It attained a speed of $1.2 \mathrm{~m} / \mathrm{s}$, and a yaw rate of 75\% $\mathrm{s}$. [12-13]. Nakashima et al. developed a two joints dolphin robot, which is $1.75 \mathrm{~m}$ long. The robot attained a propulsive speed of $1.2 \mathrm{~m} / \mathrm{s}$ and a propulsive efficiency of 0.35. [14-16]

Yet all of these achievements are not convincing enough to talk the chief designer of autonomous undersea vehicle into adopting bionic propulsion technology in his AUV project in the near future. Tangible proofs need to be put forward to show that biorobotics propulsion has remarkable advantages in some respects. At the same time, other factors also require consideration such as payloads, endurance and stability, so as not to lose too much performance of the vehicle.

Biorobotic autonomous undersea vehicle SPC-III, developed by Robotics institute, BeiHang University, is a prototype of mission-scale autonomous submersible vehicle. According to its displacement tonnage, it can be classed as portable UUV [17]. The purpose is to develop an available biorobotics propulsion device on the basis of the understanding of the mechanism of caudal fin in itinerant state as well as the current mature engineering technology. The said biorobotics propulsion device should not only improve maneuverability and reduce noise of the conventional propulsion UUV but also have acceptable speed, propulsion efficiency or endurance. Researches on SPC series biorobotics unmanned undersea vehicle started from 2001. SPC-I is a prototype used to study what impact navigation stability and yaw may have on tail fin propulsion [18]. SPC-II is a prototype used to study hovering and turning maneuverability. It achieved a yaw rate of 30o/s and a turning diameter about its body length. In 2004 it was applied in an attempt to the mission of Underwater Archaeology in Dongshan Island of Fujian undertaken by the Underwater Archaeological Team of the National Museum of China [19-20]. SPC-III has the same torpedo shape with the conventional UUV. Its two joints caudal fin thruster can be easily replaced with screw propeller. Since the hydrodynamic shape of the two are almost the same, preliminary results of the performance of various propellers has been achieved, which are used to evaluate the feasibility of applying the designed biorobotics unmanned undersea vehicle to probe commission.

The rest parts of this article are arranged as: Part 2 is a detailed description of Biorobotic autonomous undersea vehicle SPC-III, especially the realization of two joints caudal fin thruster; Part 3 presents the comparison result between propulsion power, turning radius as well as rate and screw propeller; Part 4 is a description of the result of the long-distance 
probe test carrying Water Quality Multiprobes; Part 5 discusses the performance and problems of SPC-III; Part 6 is the conclusion of this paper and the prospect for the future.

\subsection{Description of the experimental system}

1) Description of SPC-III System

SPC-III is designed to be a mission-scale vehicle; therefore its hull should have the ability to bear the pressure of water. The forward and middle sections of the hull are constructed with carbon fiber and aluminum alloy framework. The caudal section is an installed caudal fin thruster. Due to its complex shape, it is molded in the die using engineering plastics. SPC series biorobotics vehicle has two important characteristics: (1) the caudal fin thruster does not use flexible structure but expose Drive link assembly which has small volume and low weight in water. Thus conventional pressure hull and seal style can be adopted without considering the additional power consumed by flexible material for swinging deformation. (2)caudal fin is driven by two actuating DC motors, which is a comparatively mature robotics technology realizing accurate motion of caudal fin. Compared with other modes, DC actuating motors has higher electro-mechanical conversion efficiency.

As is shown in Figure 1, the forward half of SPC-III is comprised of equipment and the payload capsule, with the IFLY40 Autopilot used to control Small UAVs installed at the front. IFLY40 was successfully applied to the 24th Chinese National Antarctic Research Expedition in December 2007, finishing the task of sea ice investigation [21]. It can provide the data of posture, course angle, position and altitude and has five PID control devices. The only difference is that the barometric sensor is replaced with the water pressure sensor, which provides depth control of $0 \sim 50 \mathrm{~m}$. Below the Autopilot is an instrument for AD transfer and recording. At the back is the movement controller of caudal fin thruster, which will be introduced in details in the following part of this paper. The middle section is the dynamic cabin, which is composed of dynamic units formed by 28 pieces of 84 -watt Li-poly batteries and providing permanent endurance for SPC-III. On the top of the dorsal fin is GPS antenna of the Autopilot.

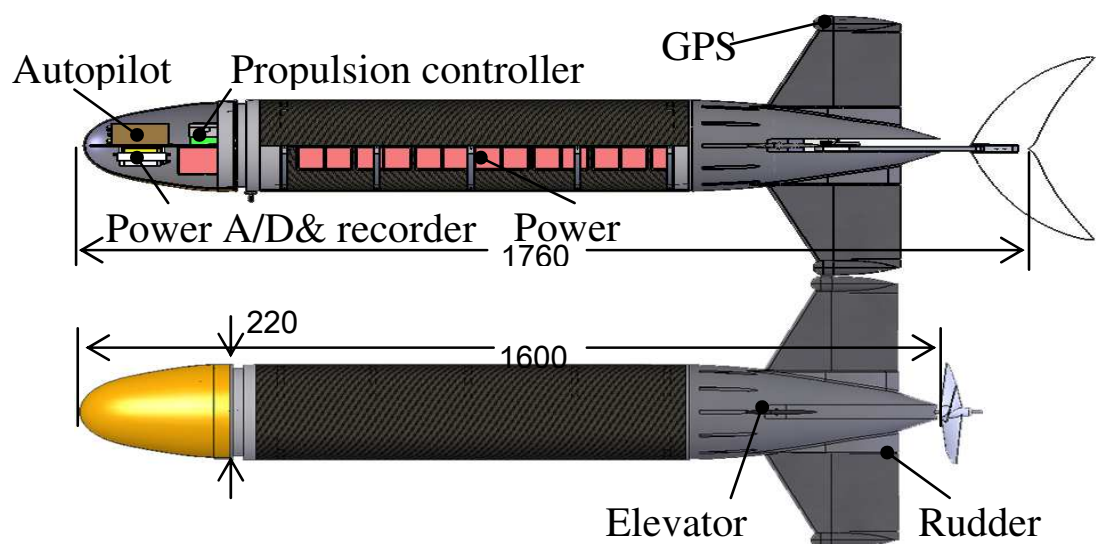

Fig. 8. SPC-III biorobotics AUV and the Comparison AUV with a screw propeller 
2) Caudal fin thruster and its control law

As is shown in Figure 2, caudal fin which generates thrust forces is installed at the end of the Drive link assembly. The caudal fin is made of $1 \mathrm{~mm}$-thick carbon fiber and imitates the shape of caudal fin of tuna, but with a lower aspect ratio. Dimension data is shown in Table 1. Link 1 and Link 2 are respectively driven by a Maxon RE40 $24 \mathrm{~V}$ motors trough reducers with reduction ratio of 30 . Let flapping amplitude of the caudal fin be A, attack angle of relative stream be $\alpha$, and $\theta_{1}, \theta_{2}$ be the respective output angle of the two motors through the reducer. And then the relationship can be expressed as:

$$
\left\{\begin{array}{l}
A=L \sin \theta_{1} \\
\alpha=\theta_{2}
\end{array}\right.
$$

In itinerant state, the performance effectiveness of caudal fin is affected by the following parameters [13]. They are (1) Dimensionless flapping amplitude, which is defined as $\mathrm{H}=\mathrm{A}_{0} / \mathrm{c}_{0}$, where $\mathrm{A}_{0}$ is the peak of flapping. (2) attack angle amplitude of caudal fin: $\mathrm{a}_{0}$. (3) phase difference of the former two: $\Phi$. (4) Strouhal number, which is defined as $S t .=f A_{0} / V$, where. $\mathrm{V}$ is the speed of inflow. Motion law of caudal fin of caudal fin propulsion marine animals like dolphin and tuna can be expressed as:

$$
\left\{\begin{array}{l}
A=1 / 2 A_{0} \cos (2 \pi t) \\
\alpha=\alpha_{0} \cos (2 \pi t-\phi)
\end{array}\right.
$$

Thus it is clear that accurate adjustment of the former three factors can be realized only by adjusting motion law of output $\theta_{1} \theta_{2}$ of motors. As the control system of caudal fin thruster, a 2-Axis motion coordinator is used generate the above motion law. As for the optimum range of the four parameters, previous work has derived preliminary conclusions [7-9][22]. Part of the results obtained by the self-propelled SPC-III in open sea will be shown in the experiments introduced in the following part of this paper.

As it is difficult to install two driving units in the narrow cone space of the caudal section, a very thin spur gear reducer is customized. At the same time, motors-reducer-sealing assembly are put in staggered arrangement to complete the assembly of caudal fin thruster. Thus it is impossible to add more torque and speed sensors.
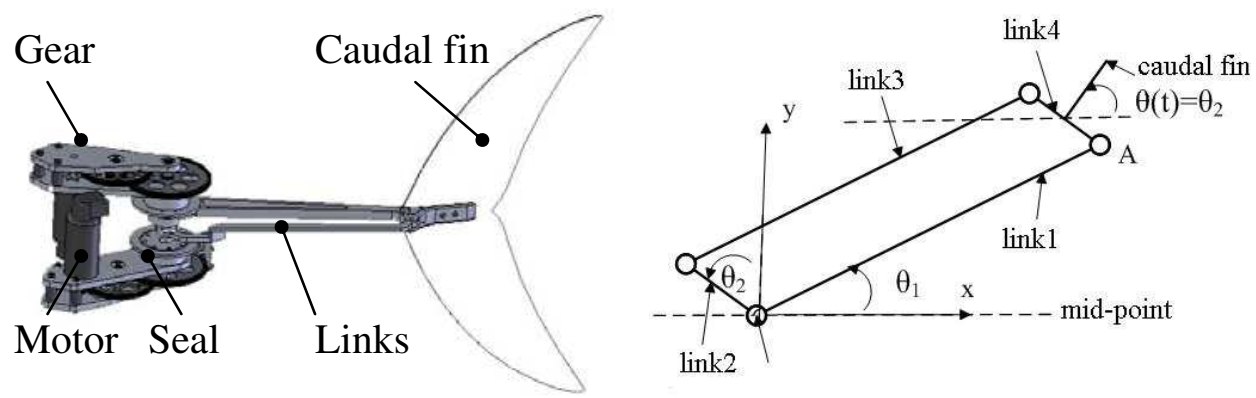

Fig. 9. The mechanical sketch of caudal fin thruster 
3) Propeller comparing AUV

The building of a AUV experimental platform used for comparison is actually to directly replace caudal fin thruster with screw propeller on SPC-III, while dynamic units, motion coordinator and amplifier remain the same. Thus difference factors are reduced. The selection and production of the propeller have got the help of China Ship Scientific Research Center (CSSRC). Open water efficiency $\eta_{0}$ of the propeller in five sections is predicted to be 0.67 [23]. The structure of screw propeller is shown in Figure 3. Parameter comparison between it and caudal fin thruster is shown in Table 1.

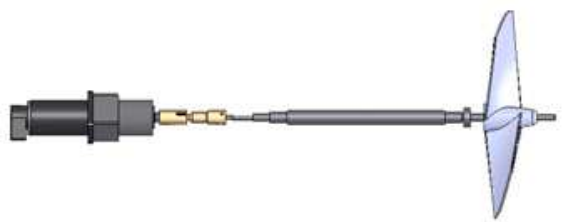

Fig. 10. Structure diagram of the screw propeller

\begin{tabular}{|c|c|c|c|}
\hline \multicolumn{2}{|c|}{ Caudal fin propeller } & \multicolumn{2}{|c|}{ Screw propeller } \\
\hline $\begin{array}{l}\text { Area of caudal fin: } \\
\qquad S\left(\mathrm{~mm}^{2}\right)\end{array}$ & 25287 & $\begin{array}{l}\text { Diameter: } \\
D(\mathrm{~mm})\end{array}$ & 240 \\
\hline $\begin{array}{l}\text { Maximum chord length: } \\
\qquad c_{0}(\mathrm{~mm})\end{array}$ & 120 & $\begin{array}{c}\text { Number of blades: } \\
\text { Z }\end{array}$ & 3 \\
\hline $\begin{array}{l}\text { Average chord length: } \\
\qquad c(\mathrm{~mm})\end{array}$ & 70 & $\begin{array}{l}\text { Expanded area ratio: } \\
\qquad A_{\mathrm{E}} / A_{0}\end{array}$ & 0.36 \\
\hline $\begin{array}{l}\text { Lead edge sweepback } \\
\text { (deg.) }\end{array}$ & 47 & $\begin{array}{l}\text { pitch ratio } \\
(P / D): 0.7 \mathrm{R}\end{array}$ & 0.837 \\
\hline Airfoil & $1 \mathrm{~mm}$ flat plate & Airfoil & NACA66mod $\mathrm{a}=0.8$ \\
\hline Length of Link1,3 (mm) & 280 & $\begin{array}{l}\text { Hub radial ratio: } \\
\qquad d_{\mathrm{h}} / D\end{array}$ & 0.18 \\
\hline Length of Link2,4 (mm) & 28 & Rotation direction & Right \\
\hline Driving motors & $\begin{array}{c}\text { RE } 40 \\
(150 w) \times 2\end{array}$ & Driving motors & $\begin{array}{c}\text { RE } 40 \\
(150 w) \times 1\end{array}$ \\
\hline Reducer & $\begin{array}{l}\quad i=30 \\
\text { (grade } 2 \text { spur } \\
\text { gear) }\end{array}$ & Reducer & $\begin{array}{c}\quad i=5 \\
\text { (grade } 1 \text { planetary } \\
\text { gear) }\end{array}$ \\
\hline Weight (kg.) & 3.3 & Weight (kg.) & 2.1 \\
\hline
\end{tabular}

Table 3. Comparison between caudal fin thruster and screw propeller

\subsection{Experiment on propulsion and maneuverability}

1) Measurement system

The test system of the complete SPC-III is shown in Figure 4. IFLY40 Autopilot provides it with perfect telemetry function. This paper is focused on power of the propeller, as well as speed, maneuverability of the vehicle. All collected data are added into the protocol through Autopilot before they are sent to the ground station software. The transmission speed is adjustable within the range of $1 \sim 10$ frames. 


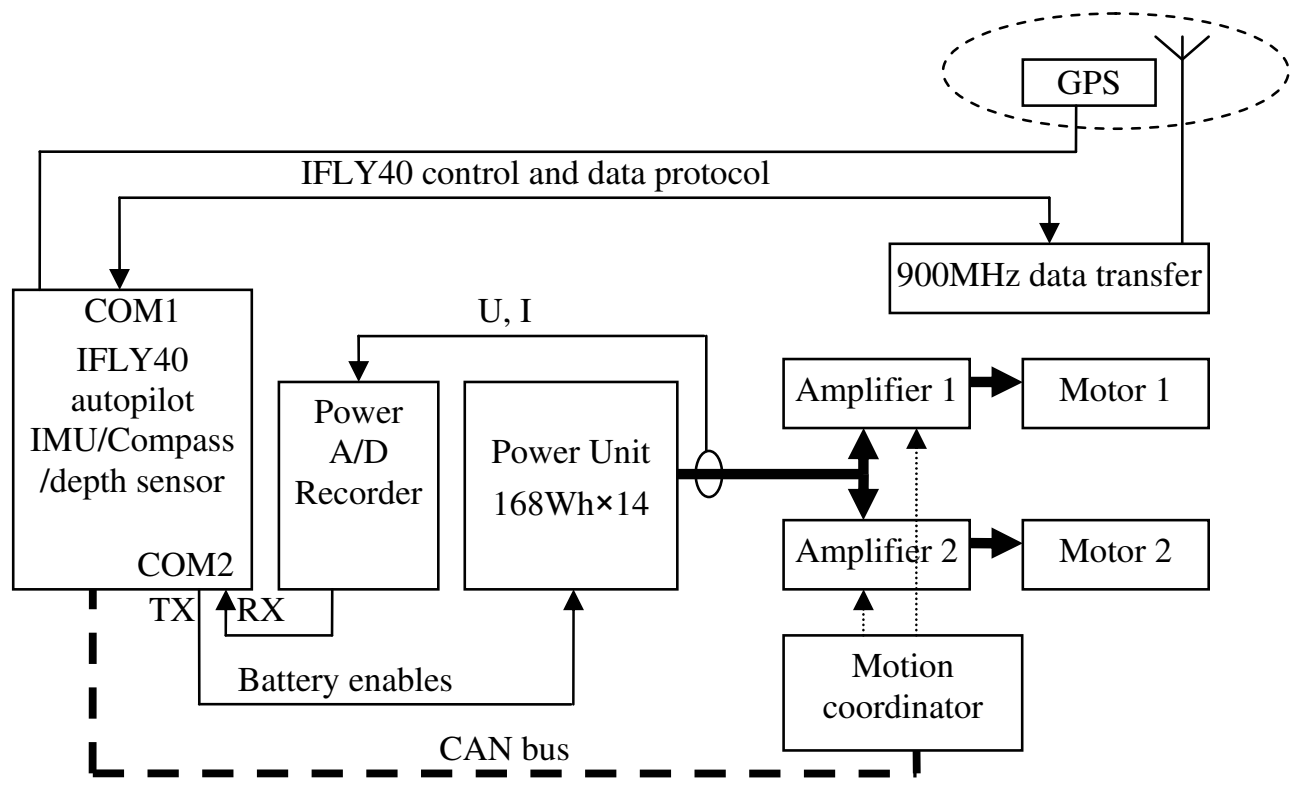

Fig. 11. SPC-III AUV electrical system

- Vehicle velocity measurement. IFLY40 Autopilot possesses various navigating modes such as UAV and RPV, which provides advantage for the vehicle to keep course or route for a long time to have tests. Therefore, this paper directly takes the longitudelatitude co-ordinate sent back by Autopilot as the original data to calculate distance and speed. Positioning of the GPS has accuracy as high as $2.5 \mathrm{~m}(\mathrm{CEP})$. Comparatively accurate average speed can be achieved if distance long enough is used for calculation. In this paper, data of 200 seconds are used for the calculation of distance and speed.

- Power measurement. A 16-bit 8-channel A/D embedded computer is adopted for the measurement of power. Sampling frequency is $100 \mathrm{~Hz}$. Integrating Calculation over power is carried out every second. Through Autopilot, power obtained is sent to Ground Control System (GCS) software, which records the data frame. Under the modes of Vehicle velocity measurement and power measurement, transmission speed of Autopilot is one frame per second. Similar to Vehicle velocity measurement, average value is also got by calculating data of 200 seconds under power measurement. Nodes of current and voltage measurement are set on the circuit through which the batteries supply power to the amplifier; therefore the power measured is all the power that consumed by the propeller.

- Yaw rate measurement. Under the mode of maneuverability measurement, the speed of Autopilot increases to 10 frames per second. IFLY40 adopts data fusion algorithm to synthesize outputs of IMU and electronic compass into a course angle that is hard to be disturbed and can cause drift.

2) The comparison of propulsion performance

From the $9^{\text {th }}$ to the $13^{\text {th }}$ of October, 2006, Comparative experiment on SPC-III and its propeller was carried out on the coast of Qinhuangdao which is located in the west coast of the Bohai Sea. As is shown in Figure 5, the experiment was carried in calm offshore waters 
at ebb time every day. Firstly, static power and zero-load power of the propeller were measured. The results show that the power of caudal fin and screw propeller at static state are respectively 7 Watt and 3.5 Watt, correspondent to the static power of two amplifiers and one amplifier. Zero-load power refers to the motion power of the propulsion system except caudal fin and screw, including all transmission loss. At this stage, because of more complicated mechanical structures, the power of caudal fin thruster is higher than that of screw propeller. The former is 25 watt at $2.5 \mathrm{~Hz}$, while the latter is 18 watt at the speed of 10 turnings per second.

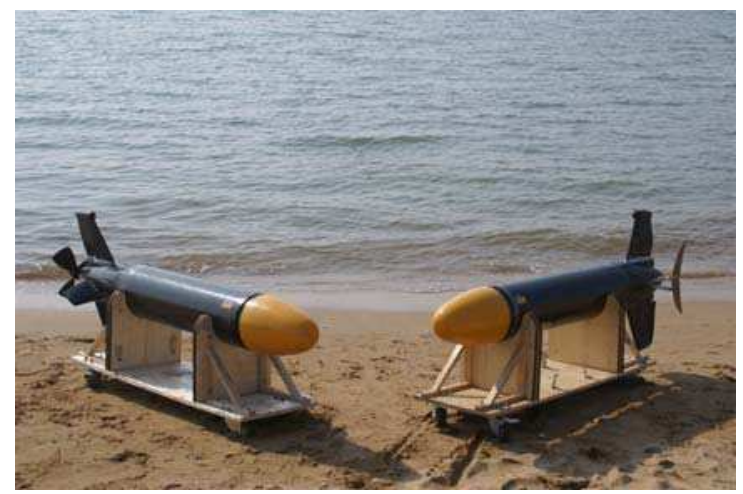

Fig. 12. SPC-III biorobotics AUV (the right one) and the Comparison AUV (the left one) on the beach

Measurement in water. Firstly, the posture of the vehicle was adjusted to level. To ensure that GPS could receive stable signals and that the wireless data transfer device could work in good condition, draft was adjusted until GPS was $0.2 \mathrm{~m}$ above water. To avoid influence from the control system, instead of starting the course control function of the Autopilot, the neutral position of caudal fin flapping or the deviation angle of rudder were adjusted manually to keep the vehicle in a linear trajectory. Note that the rudder is disabled when caudal fin thruster is used.

The measurement of power and Vehicle velocity was carried out continuously. After Autopilot was set with new frequency, rotation speed and flapping parameters through Ground Control Software GCS300, the vehicle was meticulously adjusted to keep it in a linear trajectory. This stable status was kept for a few minutes to allow the GPS time recorded. Relevant measurement data was searched according to the GPS time for later data processing. As is shown in Figure 6, 7,8, the final test results indicate that at $2.5 \mathrm{~Hz}, \mathrm{H}=1.5$, caudal fin thruster achieves maximum speed $1.36 \mathrm{~m} / \mathrm{s}$. At that moment, the total power of the propeller is 161watt; screw propeller achieves maximum speed $1.4 \mathrm{~m} / \mathrm{s}$ at the speed of 10 turnings/sec. At that moment, the total power of the screw propeller is $165 \mathrm{watt}$. The pitch of the vehicle became unstable when the flapping frequency or rotation speed was increased to increase Vehicle velocity. Another reason may be that resistance at water surface is higher than that underwater, so that vehicle is prone to pitch and oscillation or it may submerge into the water, so that GPS can not work.

The Principle of motion law adjustment for caudal fin flapping is to generate comparatively greater thrust forces and speed for the comparison with screw propeller. Because of deformation of the carbon fiber caudal fin, there is some inconsistence between the actually 
applied motion law and the ideal value obtained through earlier work. Deformation of the caudal fin may be explained as the increasing of attack angle and the lag of phase. Finally, the values adopted in the experiment are: $\mathrm{a}=10^{\circ}, \Phi=45^{\circ}$. At that moment greater propulsion speed is achieved. Measurement was carried out respectively when $\mathrm{H}=0.75, \mathrm{H}=1, \mathrm{H}=1.5$, and it is discovered that when $\mathrm{H}=1.5$, the output power is higher at similar frequency, and power consumption is lower at similar speed.

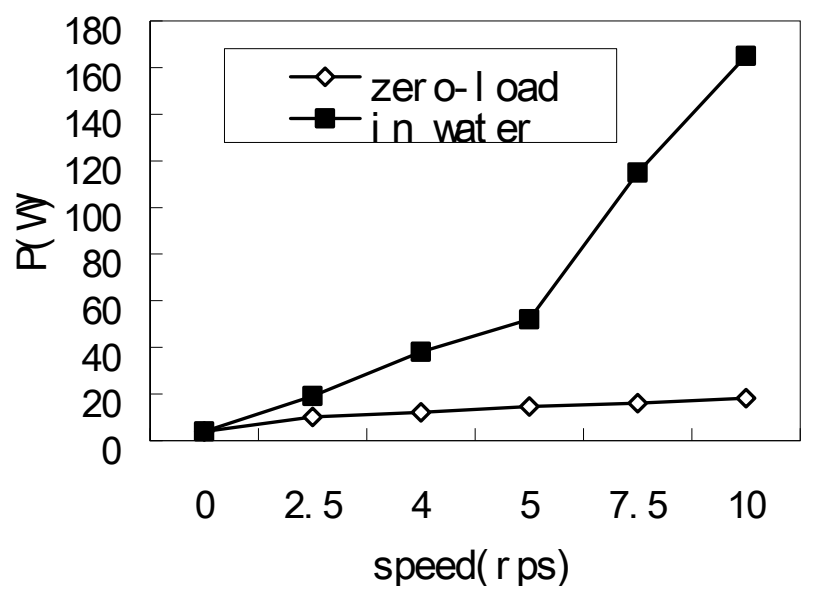

Fig. 13. Power of screw propeller in Linear Motion, "zero-load“ means the screw was not installed.

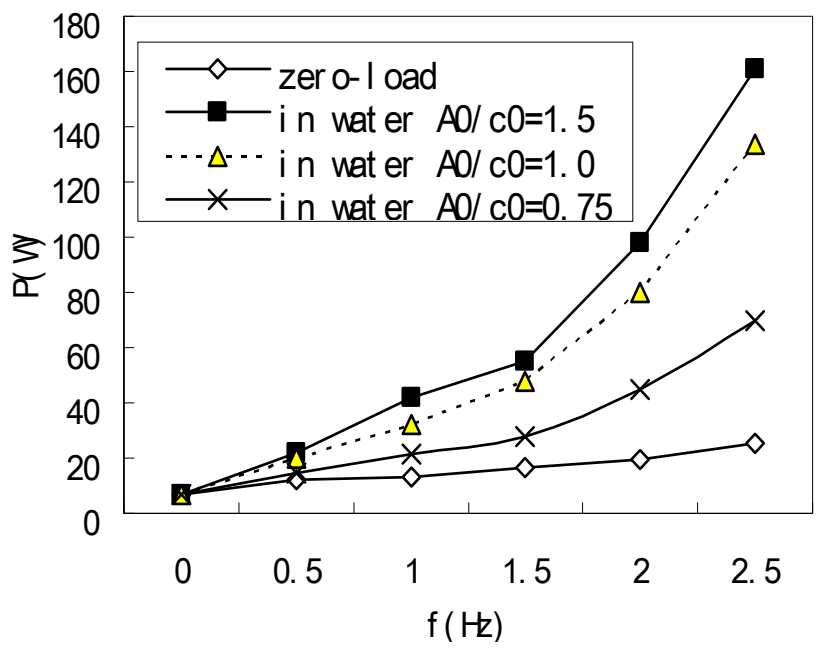

Fig. 14. Power of caudal fin thruster in Linear Motion, "zero-load” means the screw was not installed. 


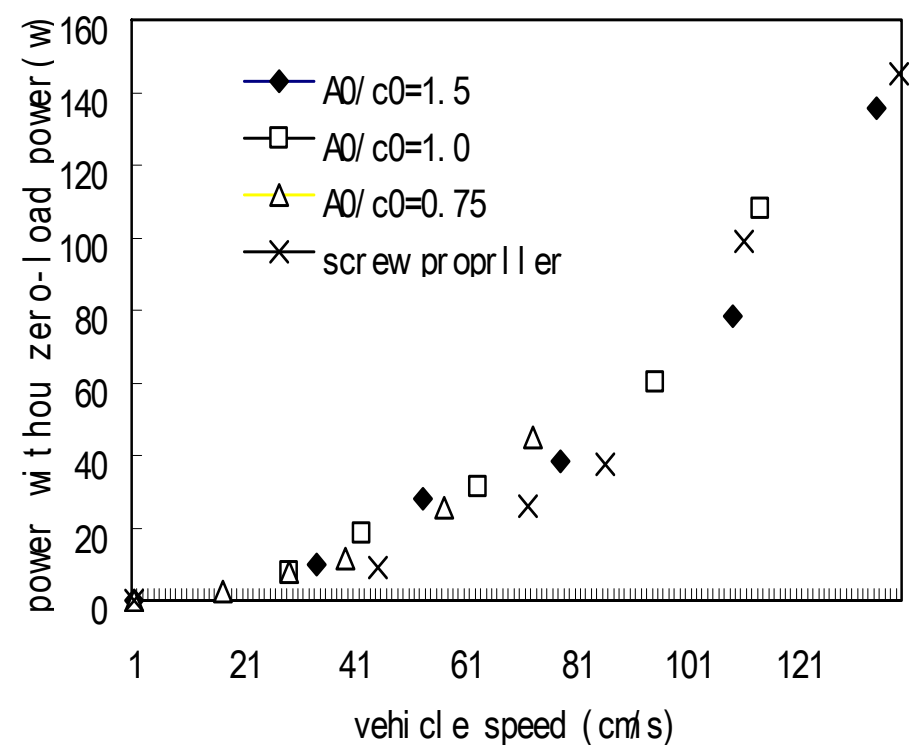

Fig. 15. Power consumption (without zero-load power) of caudal fin thruster and screw propeller

3) Measurement results of maneuverability performance

Possible commissions of portable UUV include probe of port and coast, as well as identification and destroy of torpedo [17]. To perform these commissions, AUV often needs to be close to the object in a small distance and at the same time avoids colliding. At that moment low speed maneuverability is particularly important. For example, AUV is often constrained in a narrow space when it is in the state of autonomous navigation. At that moment AUV needs to turn in situ round itself to go back to open sea, which is a maneuverability often used by ROV but difficult for AUV whose advantage lies in its cruising.

The VCUUV achieved $1.2 \mathrm{~m} / \mathrm{sec}$ and turn rates up to $75^{\circ} / \mathrm{sec}[12]$. With flexible caudal hull and four joints caudal fin driven by hydrodynamics power, VCUUV possesses excellent maneuverability. It achieves a turning diameter of two body lengths(BL). Though the hull of SPC-III is completely rigid, and it only has two joints, its special caudal structure enables caudal fin to realize a deflection angle of $0 \sim 90^{\circ}$. $90^{\circ}$ deflection angle can be used for emergency braking.

Figure 9, 10 shows the circular trajectory of SPC-III and propellers comparison AUV under maneuverability measurements. The trajectory was drawn at GCS300 ground station software using GPS Coordinate data recorded by Autopilot. Note that the calibration of the map scale is $5 \mathrm{~m}$. SPC-III adopts a flapping frequency of $2 \mathrm{~Hz}$, with a rotation speed of propeller at $7.5 \mathrm{r} / \mathrm{sec}$, and correspondent linear speed being about $1.1 \mathrm{~m}$. Yet the speed decreases remarkably as the turning radius decreases in turning state. At $45^{\circ}$ deflection angle, caudal fin thruster achieves a turning diameter of $2.5 \mathrm{BL}$, while screw propeller which uses rudder achieves a turning diameter of 5BL. Caudal fin thruster achieves minimum 
turning diameter $2 \mathrm{BL}$ at $60^{\circ}$ deflection angle. Figure 11 illustrate the results of turning speed measurement, including two kinds of data. The first data are obtained through calculation according to the time the vehicle took to finish circular route; the second data are obtained according to compass data. The two kinds of data are almost the same. At similar deflection angle, the yaw rate of Propellers AUV is about $1 / 2$ of that of caudal fin AUV.

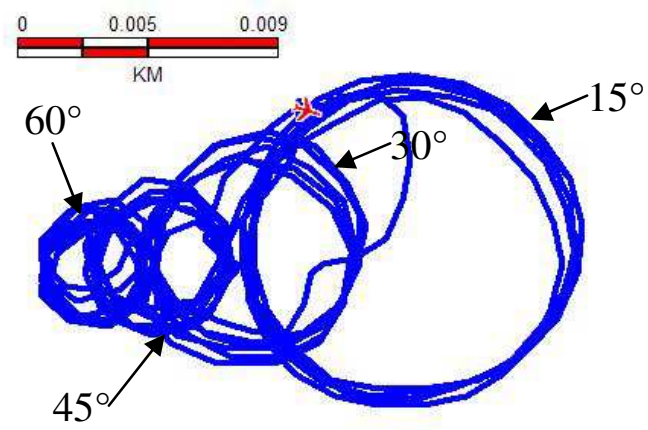

Fig.16 The trajectory of SPC-III AUV performing different caudal fin deflection at about $1.1 \mathrm{~m} / \mathrm{sec}$.

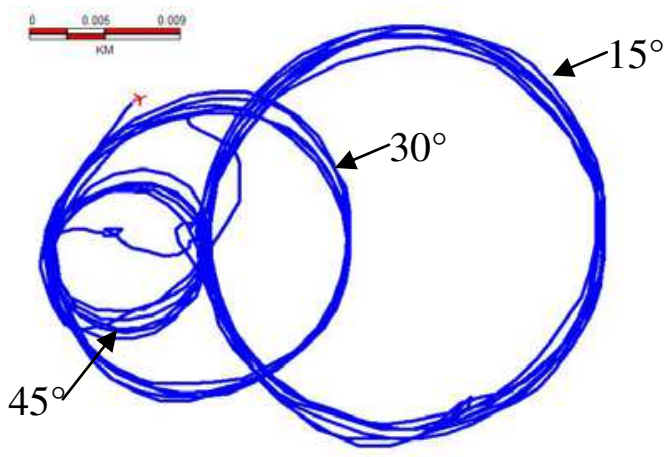

Fig. 17. the trajectory of the Comparison AUV performing different rudder deflection at about $1.1 \mathrm{~m} / \mathrm{sec}$.

\subsection{Probe experiment on blue-green algae}

Probe experiment on blue-green algae can be regarded as a commission to inspect propulsion and maneuverability performance of SPC-III. Located in the area of Changjiang Delta Region, Taihu Lake is the major water source of Wuxi. In the summer of 2007, there was a mass breakout of blue-green algae in Taihu Lake, which became the prime environmental issue harassing the local residents and government. In November 2007, carrying Water Quality Multiprobes (HACH D5X), SPC-III successfully performed a probe cruising of about $49 \mathrm{~km}$ in the water of Taihu Lake and brought back concentration distributing data of blue-green algae. Some of the probe results are shown in Table 2. Areas under heavy pollution are indicated in red in Figure 9. 


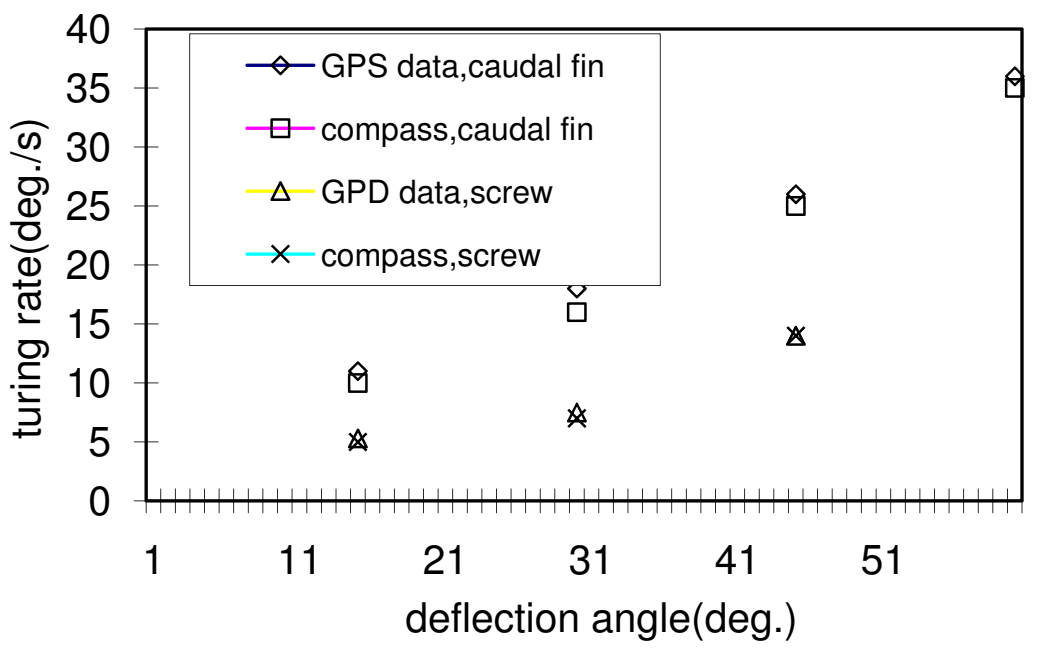

Fig. 18. Yaw rate of SPC-III and the Comparison AUV, at about $1.1 \mathrm{~m} / \mathrm{sec}$.

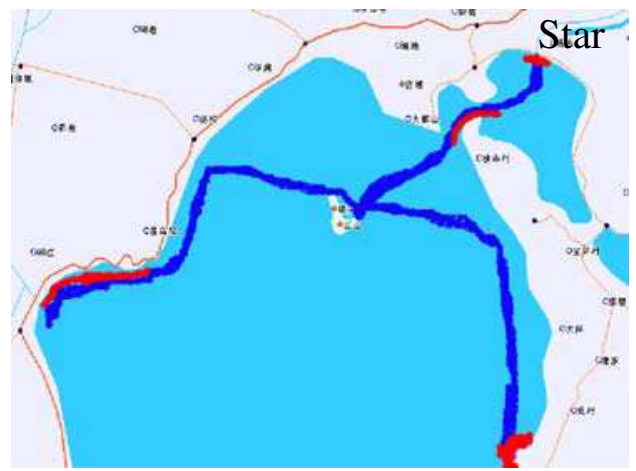

Fig. 19. Cruising trajectory of SPC-III at water quality probe on Taihu Lake shown in blue and areas under heavy pollution indicated in red

\begin{tabular}{cc}
\hline \hline Data on water quality of Taihu Lake & (November,2007) \\
\hline average PH value & 8.52 \\
maximum PH value & 9.51 \\
concentration of blue-green algae & \\
$\quad$ (center of the lake) & $3823 \mathrm{cell} / \mathrm{ml}$. \\
average pollution concentration & \\
(part of lake shore) & $288112 \mathrm{cell} / \mathrm{ml}$. \\
Maximum concentration obtained & $868120 \mathrm{cell} / \mathrm{ml}$. \\
\hline
\end{tabular}

Table 2. SPC-III brought back data carrying HACH D5X in the water of Taihu Lake 


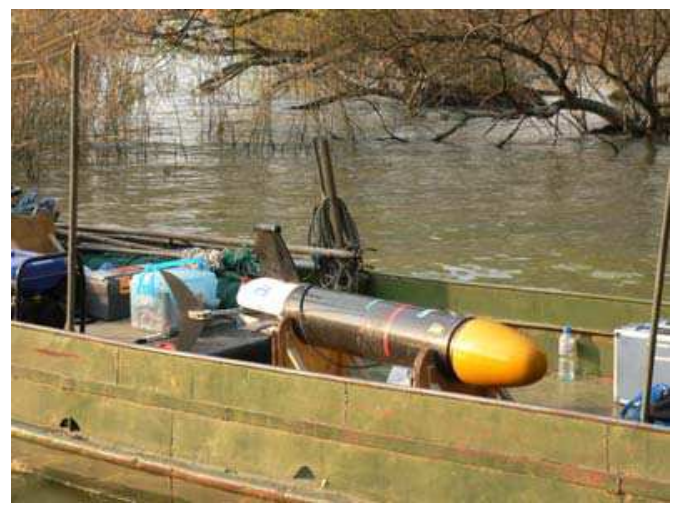

Fig. 20. working environment of SPC-III on Taihu Lake

As a portable UUV, the convenience of SPC-III was proven in the experiment on Taihu Lake. It can be plunged or fished easily by two persons manually without the usage of special ships and devices. Branches and aquatic grass near the bank are often great disaster to small propellers; yet caudal fin thruster which depends on oscillating propulsion can safely pass such area. Thus SPC-III can cruise in water area which is close to the bank and full of aquatic plants. Since blue-green algae are active in these areas, maneuverability advantage of SPCIII is very remarkable. Furthermore, nets or navigation mark often appear on the set navigation route, which requires human intervention to change the course of the vehicle. Nevertheless, relying on greater turning rate, SPC-III can take action when it is very close to the obstacles and does not need early warning. As for the obtruding aquatic bushes it met when cruising in the area a few meters from the bank, SPC-III can steer clear of them with a very small turning radius by slowing down its speed. This is very difficult for a AUV with only one propeller.

Having its batteries charged only one time, SPC-III completed its $49 \mathrm{~km}$-mission for 3 days continuously. No default was observed on caudal fin thruster. The reliability of this kind of propeller was preliminarily confirmed.

\subsection{Discussions}

Compared with high speed dolphin and tuna, the current biorobotics unmanned undersea vehicle still has a long way to go. Yet compared with conventional single-screw propeller AUV, SPC-III has made great progress. With small displacement tonnage, it realizes onecomponent vector converter and increases low speed maneuverability of AUV remarkably. In addition, the power of caudal fin thruster is also satisfactory. It can be said that using actuating motors to drive two joints caudal fin thruster is a feasible option with the current engineering technology. Of course, there also exist some congenital deficiencies. For example, actuating motors works in oscillation condition and its peak power is $40 \%$ higher than that at even pace at similar power output, therefore actuating motor and amplifier possess higher power redundancy. This means power density of the propeller is also reduced. This is the exact reason why Vehicle velocity of SPC-III is hard to increase. Working in oscillation condition also prevents the actuating motors and reducer from work continuously at optimum efficiency points. It is foreseeable that both electro-mechanical conversion efficiency and transmission efficiency of caudal fin thruster are lower than screw 
propeller which is in a uniform rotation. In respect of noise, since reducer is adopted, there are no strong points in terms of radiated noise. Yet flapping frequency of caudal fin is far lower than working frequency of the propeller at the same vehicle speed, which means hydrodynamics noise may be low [11]. Future work can be carried out to obtain experiment data on noise through comparison experiment.

\subsection{Conclusion}

This paper presents an alternative design scheme of two joints caudal fin thruster for portable AUV with single-screw propeller. Using this kind of caudal fin thruster, Biorobotic autonomous undersea vehicle SPC-III has a displacement tonnage of $47 \mathrm{~kg}$ and a length of $1.75 \mathrm{~m}$. The caudal fin thruster only accounts $7 \%$ of its displacement tonnage. Comparison experiment on self-propelling has been carried out on the sea. Within the speed of 2 2.7 joints, power consumption of caudal fin thruster and screw propeller is nearly the same. Maximum speed is $1.36 \mathrm{~m} / \mathrm{s}$ and Maximum turning rate is $36 \%$ s. Minimum turning diameter is $2 \mathrm{BL}$, while Minimum turning diameter of the compared propeller AUV is 5BL. Theoretically, Equipped with inside $2352 \mathrm{Wh}$ power units, endurance can reach 20 hours at two knots.

\section{Reference}

YinSheng Zhang, "Underwater Archaeology and Its Exploration Technology", Southeast Culture, no. 4, pp. 29-33, 1996.in chinese.

XiSheng Feng, "From Remotely Operated Vehicles to Autonomous Undersea Vehicles", Engineering Science, vol. 2, no. 12, pp. 29-33, Dec 2000. .in chinese.

JunFeng Huang, et al, "Remote Operated Vehicle(ROV) Dynamic Positioning Based on USBL(Ultra Short Base Line)", Control Engineering of China, vol. 9, no. 6, pp. 75-78, Nov 2002 .in chinese.

"Fish-like swimming, http://www.draper.com/tuna_web/vcuuc.html.

F. E. Fish and J. J. Rohr, "Review of dolphin hydrodynamics and swimming performance," United State Navy Technical Report 1801, Aug.1999.

T. G. Lang, T. Y. Wu, C. J. Brokaw, and C. Brennen, "Speed, power, and drag measurements of dolphins and porpoises." Swimming and Flying in Nature, pp. 553-571, Eds. Plenum Press, New York, NY, 1975.

Oscillating foils of high propulsive efficiency. J. M. Anderson, K. Streitlien et al. [J] Fluid Mech., 1998, 360: 41-72.

Drag Reduction in Fish-like Locomotion. D.S.Barrett, M.S.Triantafyllou, et al. [J] Fluids Mechanics. 1999,392:183-212.

M.S.Triantafyllou, G.S. Triantafyllou, D.K.P. Yue. Hydrodynamics of Fishlike Swimming [J]. Annu. Rev. Fluid Mech. 2000, 32: 33-53

Cheng JY,Zhuang LX,Tong BG.Analysis of swimming three-dimensional waing plate.J Fluid Mech,1991,232:341 355

P. R. Bandyopadhyay, "Trends in biorobotic autonomous undersea vehicles," IEEE J. Oceanic Eng., vol. 30, no. 1, pp. 109-139, Jan. 2005.

J. M. Anderson and N. K. Chhabra, Maneuvering and stability performance of a robotic tuna, Integ. Comp. Biol., vol. 42, 118-126, 2002. 
J.M.Anderson and P.A. Kerrebrock. The Vorticity Control Unmanned Undersea Vehicle(VCUUV)-An autonomous vehicle employing fish swimming propulsion and maneuvering [C]. Proc.10th Int. Symp. Unmanned Untethered Submersible Technology. NH, sept, 1997: 189-195

M. Nakashima, K. Tokuo, K. Aminaga, K. Ono. Experimental Study of a Self-Propelled Twojoint Dolphin Robot. Proceedings of the Ninth International Offsore and Polar Engineering Conference. 1999:419-424

M. Nakashima and K. Ono, "Development of a two-joint dolphin robot," in Neurotechnology for Biomimetic Robots, J. Ayers, J. L. Davis, and A.Rudolph, Eds. Cambridge, MA: MIT Press, 2002.

M. Nakashima, Y. Takahashi, T. Tsubaki, and K. Ono, “Threedimensional maneuverability of a dolphin robot (roll control and loop-theloop motion), Proc. of the 2nd International Symposium on Aqua Bio-Mechanisms, 2003, CD-ROM: S.6-10.

Fletcher, B. UUV master plan: a vision for navy UUV development, OCEANS 2000 MTS, 2000:65-71

Liang Jianhong,Wang Tianmiao,Zou Dan,Wang Song,Wang Ye, Trial Voyage of "SPC-II" Fish Robot, transaction of Beihang University,2005,31(7):709-713.

Tianmiao Wang, Jianhong Liang. Stabilization Based Design and Experimental Research of a Fish Robot. the proceeding of IEEE IROS2005,2005: 954 -959

JianHong Liang, TianMiao Wang, Song Wang, Dan Zou , Jian Sun, Experiment of Robofish Aided Underwater Archaeology, the proceeding of IEEE ROBIO2005,2005.

http:/ / www.ifly-uav.com/viewintranews.asp?id=6\&menu=news

JianHong Liang, 2006,Propulsive Mechanism of Bionic Undersea Vehicle, Ph.D. Diss., BEIHANG University, Beijing

Liangmei Ying, Jianliang Zhu ,Screw design and implementary on Comparison UUV, Report of CSSRC ,2006 


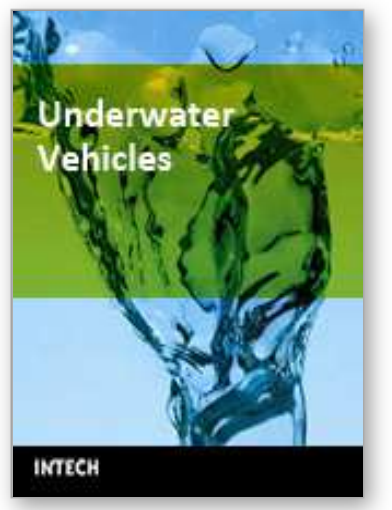

\author{
Underwater Vehicles \\ Edited by Alexander V. Inzartsev
}

ISBN 978-953-7619-49-7

Hard cover, 582 pages

Publisher InTech

Published online 01, January, 2009

Published in print edition January, 2009

For the latest twenty to thirty years, a significant number of AUVs has been created for the solving of wide spectrum of scientific and applied tasks of ocean development and research. For the short time period the AUVs have shown the efficiency at performance of complex search and inspection works and opened a number of new important applications. Initially the information about AUVs had mainly review-advertising character but now more attention is paid to practical achievements, problems and systems technologies. AUVs are losing their prototype status and have become a fully operational, reliable and effective tool and modern multi-purpose AUVs represent the new class of underwater robotic objects with inherent tasks and practical applications, particular features of technology, systems structure and functional properties.

\title{
How to reference
}

In order to correctly reference this scholarly work, feel free to copy and paste the following:

Jianhong Liang, Hongxing Wei, Tianmiao Wang, Li Wen, Song Wang and Miao Liu (2009). Experimental Research on Biorobotic Autonomous Undersea Vehicle, Underwater Vehicles, Alexander V. Inzartsev (Ed.), ISBN: 978-953-7619-49-7, InTech, Available from:

http://www.intechopen.com/books/underwater_vehicles/experimental_research_on_biorobotic_autonomous_u ndersea_vehicle

\section{INTECH}

open science | open minds

\author{
InTech Europe \\ University Campus STeP Ri \\ Slavka Krautzeka 83/A \\ 51000 Rijeka, Croatia \\ Phone: +385 (51) 770447 \\ Fax: +385 (51) 686166 \\ www.intechopen.com
}

\author{
InTech China \\ Unit 405, Office Block, Hotel Equatorial Shanghai \\ No.65, Yan An Road (West), Shanghai, 200040, China \\ 中国上海市延安西路65号上海国际贵都大饭店办公楼405单元 \\ Phone: +86-21-62489820 \\ Fax: +86-21-62489821
}


(C) 2009 The Author(s). Licensee IntechOpen. This chapter is distributed under the terms of the Creative Commons Attribution-NonCommercialShareAlike-3.0 License, which permits use, distribution and reproduction for non-commercial purposes, provided the original is properly cited and derivative works building on this content are distributed under the same license. 